\title{
The Back-Office of E-Government (Managing Information Domains as Political Economies)
}

\author{
Vincent Homburg and Victor Bekkers \\ Erasmus University Rotterdam \\ Faculty of Social Sciences \\ Center for Public Management \\ PO Box 1738 \\ NL3000DR Rotterdam, The Netherlands \\ E-mail: homburg@fsw.eur.nl, bekkers@fsw.eur.nl
}

\begin{abstract}
Many governmental organizations nowadays are setting up e-government initiatives to improve the delivery of services to citizens. Often, these initiatives require information exchange in networks of various governmental organizations in so-called back-offices. In this article, resource dependence theory and information property rights theory are used to analyze the complex mixture of cooperation and conflict that arises in these networks. The authors conclude that the use of novel process management techniques is a promising and fruitful alternative to the use of more 'traditional' project management techniques in the development of interorganizational, back-office information systems.
\end{abstract}

\section{Introduction}

In the literature on e-government, often the focus is on the organization of the front-office, and on the interaction between governmental agencies and citizens. However, in order for e-government initiatives to be successful, backoffice operations, and, more specifically, back office streamlining, have to be taken care of, too [1]. In a sense, back-office operations are the backbone of any form of egovernment, and they may require information exchange and knowledge sharing between various units, departments or organizations. In other words, back-office operations can be regarded as a Government-ToGovernment (G2G) interaction.

Wimmer, Traunmüller and Lenk describe a scenario in which "organizational boundaries will fade and give way to innovative organizational design. In this way, cooperation between administrative agencies will span wide: over distances, across organizational boundaries and even across hierarchical echelons" $[2$, p. 1 , see also [1, 5]].

Actual e-government applications, however, show that the practice of e-government may not be as attractive as some of its benevolent proponents might claim. Back offices can be regarded as networks of organizations in which goals do not necessarily overlap and interests may collide. In practice, in these networks, information itself is the primary medium of value and exchange [3] and relatively uncontrolled sharing of such a powerful resource threatens information monopolies, provides those organizations who receive information with significant power gains $[4,5,6]$ and may even threaten the reason of existence of some of the organizations involved in the process of information sharing. Consequently, existing dependencies in organizational networks might be affected and it can be expected that the exchange of information in back-offices invokes a complex mixture of cooperation and conflict $[5,6,7,8]$.

In this paper, we address the following research question: what does the nature and dynamics of interorganizational relations mean for the development and implementation of e-government information systems, and what methods and strategies are used to design and implement these systems? The focus in the analysis is on the interorganizational relations that are mobilized through the integration of various back office systems [9]. In the remainder of this article, we analyze existing egovernment initiatives, and, more specifically, information relations between various back-offices, using a political economy view on information exchange [6]. Subsequently, we explore methods and strategies of ICT management in policy networks, and compare a view on ICT management as managing projects with a view indicating that ICT management also has to do with managing a process, which is directed at achieving a shared meaning or understanding about the role and contribution of ICT applications between several backoffices [10]. The paper will be concluded with lessons learned and recommendations for management approaches to be used for organizing G2G information exchange in egovernment initiatives. 
This article is structured as follows. In section two, some preliminary remarks are made about the topology of the Dutch system of governance, which may help to clarify the empirical setting and the analysis. The confusing mixture between conflict and cooperation in back-office interchange of information is analyzed in section three ('The Political Economy of Information Exchange'). The confrontation of the political economy of information exchange and empirical data from Dutch back-office integration efforts is documented in section four. Section five provides recommendations and lessons learned, and the article ends with conclusions in section six.

\section{The Dutch Setting: Networks of Governmental Organizations and Authentic Registrations}

In the Netherlands, the relative popularity of the New Public Management (NPM) philosophy [11] has resulted in, among other things, the breaking-down of large organizations (for example in the fields of housing, social security, employment) in networks of relatively autonomous organizations (both concerned with policy development, as well as with policy execution, administrative surveillance, and so forth). Consequently, policy networks emerged in which separate, relatively autonomous organizations execute adjacent or even slightly overlapping administrative tasks. This view of government as a network is increasingly appreciated as a means of steering complex societies in terms of coproduction and co-operative management [18].

In terms of the use of information in these networks, there is a danger that several relatively autonomous organizations gather the same type of information of citizens or corporations. In relation to e-government, one can hypothesize that transactions can be handled more efficiently if the several back-offices involved use the same data or data definitions, and thus that standardization of data is a necessary condition for successful egovernment initiatives. In order to put these ideas to work, the principle of authentic registrations has been developed. This principle states that data is gathered once at the source, and then used many times by organizations in the network. The terms of use are formalized in multilateral agreements. The ownership of authentic registrations is attributed to specific organizations who are responsible for (and ideally have an interest in) ensuring the quality of data. These specific organizations can be regarded as 'information owners'. Other organizations that need, for example, income data, do not gather these data themselves, but rather use the authentic registration. Inversely, the authentic registration can grant other organizations (designated) property rights by means of interchange agreements, but they are by definition 'residual claimants', implying that the right to allocate rights not explicitly covered by an interchange agreement, resides with the information owner.

A typical example of an authentic registration is the municipal register of citizens' residential data, but it is also possible to think of the license and vehicle registration, the authentic registration of pollution and emissions and the fiscal income registration.

In practice, if a citizen applies for an allowance or permit, her antecedents have to be checked and information exchange between various organizations (in the case of, for example, a welfare benefit: the municipal register for the appellant's address, the job agency for her enrollment, the executive institution executing unemployment schemes for her job history, et cetera) takes place.

\section{The Political Economy of Information Exchange}

\subsection{Introduction}

In the previous section, it has been illustrated that many policy processes are fragmented over several administrative organizations. The relations between these organizations are to a certain extend governed by the principle of authentic registrations. This results in information exchange and organizational redesign in the back office.

From a strictly instrumental point of view, the information relations between various organizations can be modeled in terms of secure XML document containers [12] or in terms of conversation rules, conversation classes and continuation rules using speech act theory [13].

At an institutional level, however, other sets of questions arise. These questions are related to the complex mixture of cooperation and conflict that emerges when organizations start exchanging information across traditional organizational borders $[5,6,7]$. In order to illustrate some of these questions, we firstly present some anecdotal evidence of difficulties that arise when organizations exchange information across organizational boundaries. As the difficulties we would like to emphasize 
are not typical for the public sector [5, 6, 7], the anecdotal evidence stems from governmental organizations as well as from private sector organizations.

A private sector illustration is the TransLease information system, an electronic commerce system owned by Cap Gemini and used by a thousand British repair agents working for seven vehicle leasing and contract hire companies [17]. TransLease uses standardized data formats throughout the network (which also enshrine the 'rules of trade') as the backbone of the system, in order to simplify the processing of auditing invoices. In practice, actual use of the system proved to be far below expectations. An evaluation showed that the TransLease system did not provide the envisaged mutual benefits to its participants: "[a] dominant theme for repair agent complaints was their perception of an 'unfair' balance of power, which meant they felt that lease companies would tie them into a system that would reinforce and amplify existing power structures" [17, p. $10)$.

A public sector illustration is the Criminal Justice System in the United Kingdom [18]. The UK has heavily decentralized and compartmentalized criminal justice agencies, including for instance the police, the probation service and the magistrates courts. Early work on automated support centered on an elaborate dataflow model that showed the benefits of a new information system. It was soon clear, though, that the costs and benefits were unevenly divided among the parties involved, and that the specific cultures and professional norms of the various agencies were not reflected in operational methods and information management priorities. Therefore, a more piecemeal, incremental approach was chosen, in which various professional groups (lawyers, police officers, probation officers and prison officers) were allowed idiosyncratic discourses embedded in distinctive data definitions and - standards, yet these distinctive domains were very selectively connected using EDI interfaces and e-mail links ${ }^{1}$.

Beynon-Davies, furthermore, describes an attempt to develop a generalized model of healthcare data to be used for information exchange in the British National Health Service (NHS) [20]. Despite large efforts the data model was severely resisted and has never actually been implemented. Although the development of the data model was originally portrayed as a neutral and technocratic exercise, the participating organizations very actively opposed the data model because it raised

\footnotetext{
${ }^{1}$ A similar case description exists for the Dutch value chain of penal law enforcement [19].
}

unforeseen, partly unintended and very fundamental questions about accountability within the network of cooperating organizations. Markus refers to this kind of situations as attempts to 'ferret out how the knaves are doing in the trenches' [4].

TransLease-, CJS- and the NHS-case are to a certain degree modest examples of situations in which exchange of information using information systems that cross organizational boundaries resulted in politicking, hoarding of information, sabotaging interorganizational information systems, et cetera $[4,6,8]$. These phenomena have also been observed in specific e-government initiatives where information exchange resulted in implicit or explicit data wars [21].

\subsection{Information Politics and Economic Use of Information}

From the anecdotal evidence provided so far, it is not clear why politicking, hoarding of information, and sometimes even manifest sabotage occur. In order to clarify the (intuitive) difficulties mentioned above, we turn to two streams in organization theory that focus on networks and interorganizational relations: political organization theory (more specifically: a political view on information exchange using resource dependence theory) and economic organization theory (more specifically, an economic view on information exchange using property rights theory).

\subsubsection{A Political View on Information Exchange}

Core to the TransLease and CJS illustrations is the notion of a delicate balance between 'resource dependence' of organizations in networks [16], and the nourishment of organizations' informational autonomy [6]. According to resource dependence theory [16], organizations in networks may be willing to set up and use information systems that cross organizational boundaries in order to gain access to information controlled by other organizations, but yet may be unwilling to comply with arrangements that may not be designed to suit them (i.e., information handling procedures, terms of use and data models). In fact in information partnerships, according to resource dependence theory, every organizations strives to optimize its self-interest by (1) minimizing their dependence on other organizations and (2) maximizing the dependence of other organizations on themselves. Consequently, especially standardization (for example, of 
data definitions) is a very sensitive subject as it touches upon culturally or professionally accepted procedures which may not be given up easily. Bellamy illustrates this by stating that attempts to exchange information across organizational boundaries "not only reflect the structure of information domains, but in so doing reflect, legitimate and re-produce the discourses of powerful groups, validate their ways of steering and thinking, and give tangible force for to their influence on organizational life" [18, p. 299].

Summarizing, according to resource dependence theory, information exchange, and especially standardization, may result in shifts in power balances between organizations. These shifts may even ultimately result in organizations losing their reasons to exist. It is not surprising, therefore, that organizations are very cautious in (unconditionally) exchanging information across organizational boundaries. It is unlikely that exchange of information in back-offices is an exception to this general observation.

\subsubsection{An Economic View on Information Exchange}

Although political organization theory provides an explanation for the organization-political struggle surrounding the development and use of information systems that cross organizational boundaries, decision makers or actors in general are usually less realistically depicted as aberrant managers or deviant technologists, focusing on political aspects, unconditionally nurturing organizational autonomy and ignoring effectiveness and efficiency. The politicking in relation to interorganizational information systems, however, is capable of being understood in other ways, among other things in ways that also include aspects of efficiency. In order to show how a more sophisticated understanding could throw more light on the topics under investigation here, we discuss a body of knowledge complementary to resource dependence theory, (information) property rights theory.

Property rights theory provides an analysis of behavior of individuals with respect to assets (including information assets, $[14,15])$, or behavior of organizations in G2G networks with respect to information assets. Crucial is the assumption of bounded rationality. In this context, bounded rationality refers to the impossibility to formalize all kinds of behavior in contracts that encompass all future contingencies. If we regard information systems as information assets, it is possible to analyze behavior with respect to these kind of information systems with property rights theory.

In property rights theory, the notion of 'ownership' is emphasized. Full ownership of information systems, for example, involves the right to use an information system, to modify it with quality-enhancing or cost-saving features, and to appropriate the benefits of these adaptations. Using a neoclassical line of reasoning, it can be shown that an asset owner has intensive incentives to perform well.

Because of bounded rationality, there will always be 'incompleteness' of contracts, implying that there will always be residual property rights not covered in a contract. The institution that allocates these residual rights of is ownership [14] and hence, the owner is 'residual claimant'. This situation occurs when in a network of organizations, one organization fully owns a central database while other organizations use it (that is, look in the database and/or enter information into the database) and contribute in the costs of the system through a agreedupon lease contract. Such a separation of ownership and actual use has important consequences for the behavior with respect to information assets, which can be characterized by the phrase 'rental cars are driven less carefully than cars driven by their owners' $[14]^{2}$.

For the specific situation described previously, it is relevant that the grand designs of information systems that cross organizational boundaries confronts participating organizations' with an attenuation of property rights, and hence, their incentives to perform well are partly mitigated. This mitigation of incentives results in subtle intangible costs of low effort which will eventually appear as distorted, missing, or unusable data. The line of reasoning can be summarized as follows: the more the sense of 'ownership' is diminished, the less intense incentives will be. Consequently, the level of investments in the interorganizational information system will typically be lower, which in its turn affects the functionality, profitability, and eventually the viability of information sharing.

\subsubsection{Methods and Strategies for ICT Management}

It is interesting to note how, in practice, ICT management techniques cope with the difficulties

\footnotetext{
${ }^{2}$ In property rights theory, there are two circumstances in which incentives by participants are best served by common control: strict complementarity of assets and/or strict indispensability of participants.
} 
presented by interorganizational character of many egovernment initiatives.

A typical ICT management approach towards designing and building information systems to support information exchange in the context of e-government is a project management approach. Typical for project management is that:

- a temporary endeavor is undertaken in order to create (1) a system architecture (including a standardized data format), (2) terms of use (3) and information handling procedures. These three components form the backbone of the information exchange;

- $\quad$ goals are stated in a fixed and formalized way;

- implementation is carried out in a step-by-step manner.

The attributes of project management techniques characterize the main feature of project management itself: by means of formalizing goals, by decomposing tasks into smaller tasks and by identifying standardized products to be delivered at specific moments in time, risks are reduced.

From the point of view of 'regular' policy development and/or ICT systems development, a choice for such an approach is readily understandable. The question is whether project management techniques can deal with the wide variety of interests the interorganizational character of e-government initiatives presents. For instance, the question arises how project management's attempts to formalize goals and to identify subtasks relate to the intrinsic political nature of interorganizational relations as exemplified by resource dependence theory and property rights theory. And, referring to the before mentioned TransLease-, NHS- and CJS-anecdotal evidence, the question arises whether project management's standardization and formalization attempts intensify or reduce organization-political struggle among organizations that already have suboptimal incentives to exchange information (see also [6]).

\subsection{Summary: the Political Economy of Information Exchange}

After reviewing both resource dependence theory and information property rights theory, some light is shed on the specific phenomena in the TransLease, NHS and CJS cases, and probably on issues of project management in developing interorganizational information systems in general. Standardization of data definitions and data standards that is pursued in order to exchange information across organizational boundaries may be geared to the requirements of some organizations participating in an organizational network, but not necessarily to the requirements of all organizations. In terms of resource dependence theory, standardization may intensify existing dependencies and enshrine these dependencies in the technology. In terms of information property rights theory standardization of data definitions and data standards can be conceived as a mitigation of property rights with respect to the information system. Consequently, participants are less inclined to invest in the system and to enhance the information system with cost-saving or quality-enhancing features, and eventually such a diminishment of incentives results in less profitable, less functional and even less viable interorganizational information systems. A typical symptom of lack of incentives is poor data quality, resulting from underinvestment in human and technical capital.

So, despite intuitive appeal, it may be useful to investigate the value of project management techniques.

\section{Analysis: Case Studies of Interorganizational Information Systems}

In this section, two case studies of the development of interorganizational, back-office information systems are presented here: the development of the Dutch Municipal Register of Citizens' Residential Data and development of the Dutch Vehicle Registration.

The analyses presented here are based on secondary analyses of evaluation reports of the two systems, and on interviews and observations by one of the authors of this paper.

The analysis of the cases is structured as follows: first, the policy network is described in term of history and relevant actors. Second, the development process is described in terms of goals, interests, and strategies employed by the various actors.

\subsection{Case 1: Dutch Municipal Register of Citizens' Residential Data (GBA)}

The Dutch Municipal Register of Citizens' Residential Data (GBA: Gemeentelijke Basis Administratie) is an authentic registration in which name, address, date of birth, sex, nationality, et cetera of residents in the Netherlands are recorded.

Since the 1970s, there has been a lot of discussion on the question how an authentic registration of residential data should look like. Initially the discussions evolved 
around the idea of a centralized register. However, a centralized architecture of such an information system raised fundamental issues concerning the protection of privacy and moreover, concerning the institutionalized relationships between various levels of government (i.c., the central level and the local, municipal level). In 1984, a decentralized initiative was launched: the GBA. The discussion on the GBA involved the municipalities, which, at that time, 'owned' paper-based registers, the Netherlands Association of Municipalities (the municipalities' interest association), the Ministry of the Interior and a Project Bureau (established in 1989). The Project Bureau's original task was to develop, among other things, standardized applications on behalf of the Ministry.

Gradually, the idea of a decentralized register took shape. The register was to be used and partly administered by more than 500 municipalities, while the data was to be are used by more than 300 public and private organizations.

In the decision-making processes with respect to the development of the GBA, it became clear that various conflicts of interests existed with respect to the envisaged control over (or: ownership of) the system. These conflicts existed with respect to the following domains:

- $\quad$ the control over and ownership of the GBA computer systems;

- $\quad$ the control over and ownership of the network connecting the separate systems;

- $\quad$ the control over and ownership of the data embodied in the system;

- the legal framework in which the above ownership and control issues were formalized;

- $\quad$ the division of costs and benefits over the parties involved.

In fact, it is possible to discern various arenas in the decision making with respect to the GBA. An example of such an arena is the decision making with respect to the ownership and control over applications (system level). Originally, it was the task of the Project Bureau to develop applications. The municipalities, however, thought that this would jeopardize their autonomy and they at least wanted to be able to select a system supplier by themselves.

At this moment, it is possible to conclude that there a elements of a political economy present in the decision making with respect to the GBA: over time, there were disputes with respect to the question whether there should be a centralized system or a decentralized system, and when the decision was taken to implement a decentralized system, there were more or less constant quarrels over control and ownership issues with respect to several aspects of the system. As a result, the composition of project teams changed as individual members left these groups and others joined them.

Eventually, in the process of waxing and waning, a solution was found by granting municipalities control and ownership over the data (municipalities were responsible for the acquisition, maintenance and dispersion of data), whereas central government was responsible for the system level (i.c. development of a data model, on basis of which eventually 15 system suppliers developed applications). Furthermore, the development of the legal framework took place in parallel with the development of the system itself.

\subsection{Case 2: Dutch Vehicle Registration (NKR)}

The second case concerns the development of the Vehicle Registration (NKR: Nieuwe Kenteken Registratie). The registration was initiated in 1981 and eventually put to use in 1995 . The goal of the registration was to identify owners of licensed vehicles and vessels. Uses are to be found in the fields of taxation, liability, criminal prosecution, traffic safety projects, and environmental policy. Because of this wide variety of uses, many parties were involved in the development of the register: the ministries of the Interior, Economic Affairs, Finance, Justice and Transport, Public Works and Water Management. Furthermore, also the Dutch Center for Vehicle Technology and Information and the Central Traffic Police Commission were involved. And, apart from these institutions, representatives from the automotive industry (i.e., auto repair agents) and post office branches were consulted.

The development of the register itself was carried out by a Project Organization, and involved not only the development of the system in a technical sense; it also required several changes in legislation. The intended system owner was the Center for Vehicle Technology and Information. As a consequence, this organization transformed from a relatively technically oriented expertise center to an information service provider for many governmental organizations, which in this specific case also involved the transfer of various tasks to this organization.

Many discussions took place in the Project Organization, as a result of which the Project Organization's composition changed repeatedly. At the same time, a new piece of legislation (WVW: 
Wegenverkeerswet, Act on Roads and Traffic) took place, which affected the functional requirements of the register.

In reconstructing the decision-making process, it is striking that, as happened in the GBA case, three arenas could be discerned: one in which the system was designed, one in which data ownership issues were discussied, and a legal arena in which changes in legislation were prepared. These arenas did not exactly match with the (sub)project that had been identified on beforehand; moreover, issues concerning the system, data ownership and legal issues evolved at more than one moment in time and in various (sub)projects, and sometimes at specific moments in time, issues were more or less explicitly related to each other for example the data ownership issues and legal issues.

Eventually, it has been decided to attribute data management issues related to general data (in terms of: procedures for gathering, registration, manipulation, dispersion of data) to the Center for Vehicle Technology and Information, issues related to specific data to various ministries, and to attribute system management responsibilities (system development, maintenance, educating personnel, et cetera) to the Center for Vehicle Technology and Information. In such a way, a division of tasks could be conceived that was technologically speaking, intrinsically complex, but more or less compatible with the (institutional) diversity of interests.

\section{Reflection and Lessons Learned}

In the cases of GBA and the NKR, we have seen that organizational-political and economic logic resulted in very sensitive decision-making processes regarding the development of interorganizational information systems. In both cases, a project management approach was chosen in order to minimize risks. Various subprojects were identified, and this contributed to the oversight of the whole project.

It is striking that in both cases, discussions and struggle took place in arenas, that did not overlap with the subprojects that had been defined on beforehand. Moreover, arenas and (sub)projects were intertwined. In this respect, the emergence of arenas in which issues are discussed is not a feature of project management; these arenas were not identified on beforehand and the solutions to the complex problems were achieved by coupling issues from various arenas at strategic moments in time (e.g., the coupling of legal issues with issues regarding system and data management can be characterized as making use of windows of opportunity rather than of deliberate, prespecified choices). With respect to these characteristics, it can be concluded that project management techniques did not match the specific nature and dynamics of the interorganizational relationships as analyzed in section three.

In the literature on complex decision making, there seems to be an increased appreciation for specific techniques that are expected to be able to better fit the dynamics and nature of networks and interorganizational relationships than project management techniques do, namely process management techniques [10]. Characteristics of project management techniques and process management techniques are contrasted in Table 1. Crucial to the distinction between project management techniques and process management techniques is that in project management techniques, by means of decomposition, risks of random events are minimized. By using process management, the fact is accepted that decision-making takes place in various arenas which are not defined on beforehand; the element of risk in terms of policy windows or windows of opportunities as perceived by the parties involved is a solution to problems rather than a phenomenon to be ignored. It is the explicit role of the process manager to have a sharp eye for policy windows as random events, as these events provide the opportunity to couple decision making in various arenas. In doing so, it is very likely that solutions can be reached that are impossible to accomplish using regular project management techniques.

The development process of GBA and NKR is probably better understood from the point of view of process management than from the point of view of project management. Therefore, we claim that process management techniques provide a more fruitful alternative to project management techniques as the former seem to be more able to deal with the dynamics and nature of interorganizational relationships than the latter can.

Therefore, the use of process management techniques in the development of interorganizational information systems (and: in the integration of back offices) provides a promising perspective on the problem of integrating the back-office of e-government initiatives. Central to the idea of process management of (interorganizational) ICT is that managing interorganizational ICT requires attention to processes of 'consensus building' and 'cooperative behavior' rather than that of a step-by-step development of an ICT architecture. As the process of 'consensus building' and 'establishing cooperative behavior' is very hard to achieve on beforehand, process management's goal-seeking behavior (within general constraints) is more appealing than project management's goal formalization. 
Table 1: project- and process management characteristics (adapted from [10])

\begin{tabular}{|c|c|c|}
\hline & $\begin{array}{l}\text { Project } \\
\text { Management }\end{array}$ & $\begin{array}{l}\text { Process } \\
\text { Management }\end{array}$ \\
\hline Activities & Unique & Multiple \\
\hline $\operatorname{Goal}(s)$ & $\begin{array}{l}\text { Singular, under } \\
\text { shared regime }\end{array}$ & $\begin{array}{l}\text { Various, under } \\
\text { shared regime }\end{array}$ \\
\hline Orientation & Short term & Long term \\
\hline Culture & Heterogeneous & $\begin{array}{l}\text { Heterogeneous, } \\
\text { ambiguous and } \\
\text { dynamic }\end{array}$ \\
\hline Orge & $\begin{array}{l}\text { Temporary } \\
\text { project } \\
\text { organization }\end{array}$ & $\begin{array}{l}\text { Interorganizational } \\
\text { interactions to } \\
\text { coordinate } \\
\text { behavior }\end{array}$ \\
\hline Env & $\begin{array}{l}\text { Uncertainty with } \\
\text { respect to } \\
\text { performance, } \\
\text { costs, schedule }\end{array}$ & $\begin{array}{l}\text { Ambiguity with } \\
\text { respect to } \\
\text { performance, costs, } \\
\text { schedule }\end{array}$ \\
\hline $\begin{array}{l}\text { Conventions } \\
\text { and } \\
\text { procedures }\end{array}$ & $\begin{array}{l}\text { Affects existing } \\
\text { conventions and } \\
\text { procedures }\end{array}$ & $\begin{array}{l}\text { Seeks } \\
\text { conventions } \\
\text { procedures }\end{array}$ \\
\hline
\end{tabular}

\section{Conclusions}

In this paper, we have analyzed information exchanges that take place under the heading of (in this case, Dutch) e-government initiatives. These projects often involve many governmental organizations.

By using a political economy point of view on exchanging information in networks of organizations, it is stated that information exchange is a very sensitive subject. This premise has been illustrated by presenting anecdotal evidence of the TransLease-, NHS- and CJS cases. The sensitivity can be explained by the fact that developing and implementing interorganizational information systems often implies standardization in some form and standardization may - in a very subtle way amplify existing dependencies among organizations or mitigate incentives to perform well. Consequently, participants are less inclined to invest energy, effort and money in the development of the system and to enhance the information system with cost-saving or qualityenhancing features. Eventually, such a diminishment of incentives results in less profitable, less functional and even less viable interorganizational information systems. In practice, even data wars have been observed that were associated with the specific nature and dynamics of interorganizational relations.

In the observed GBA and NKR cases, consensus building and creating shared meaning, rather than topdown ICT formalization and standardization, were important. Consensus building and creating shared meaning in the GBA and NKR cases took place in a process of coupling of issues in various arenas, which emerged throughout the process and were not identified on beforehand.

It can be concluded that in complex interorganizational ICT initiatives, such as those in which achieving integration in back-office e-government initiatives is emphasized, project management approaches may be less fruitful than methods and strategies in which the emphasis is on goal-seeking, identifying win-win situations and coupling issues in various arenas (for example, a system design arena, a data ownership arena and a legislation arena). In the literature, process management approaches have been suggested that are better suited to deal with these issues than project management approaches can. Therefore, it is concluded that as e-government initiatives can be characterized as political economies, it is important to be able to build consensus and to couple issues between various arenas in e-government initiatives. Process management techniques provide interesting and fruitful strategies to deal with these challenges, and are therefore an attractive alternative to 'traditional' project management techniques in ensuring viable e-government initiatives.

\section{References:}

[1] Bekkers, V.J.J.M. (1998). Wiring Public Organizations and Changing Organizational Juridisctions. In: Snellen, I.Th.M., W.B.H.J. van de Donk. Public Administration in an Information Age. Amsterdam: IOS Press. Pp. 57 - 77.

[2] Wimmer, M., R. Traunmüller, K. Lenk. (2001). Electronic Business Invading the Public Sector: Considerations on Change and Design. Proceedings of the $34^{\text {th }}$ Hawaii International Conference on Information Systems. 
[3] Davenport, T.H., R.G. Eccles, L. Prusak. (1992). Information Politics. Sloan Management Review. Fall. pp. 53-65.

[4] Markus, M.L. (1983). Politics and MIS Implementation. Communications of the ACM. pp. 430440.

[5] Bekkers, V.J.J.M. (1998). Grenzeloze Overheid (Government without Frontiers). Alphen a/d Rijn: Samsom.

[6] Homburg, V.M.F. (1999). The Political Economy of Information Management (A Theoretical and Empirical Analysis of Decision Making regarding Interorganizational Information Systems). Groningen: SOM / Capelle a/d IJssel: Labyrint.

[7] Kumar, K., H.G. van Dissel (1996). Sustainable collaboration: managing conflict and collaboration in inter-organizational systems. MIS Quarterly, 20(3), 279300 .

[8] Knights, D, F. Murray. (1992). Politics and Pain in Managing Information Technology. A Case Study in Insurance. Organization Studies. 13(2). pp. 211-228.

[9] Cunningham, C., C. Tynan. (1993). Electronic Trading, Inter-organizational Systems and the Nature of Buyer-Seller Relationships: The Need for a Network Perspective. International Journal of Information Management. 13(1). pp. 3-28.

[10] Bruijn, J.A. de, E.F. ten Heuvelhof, R.J. In 't Veld - (1998). Procesmanagement, over procesontwerp en besluitvorming. (Process management, on process design and decision making). Schoonhoven: Academic Service.

[11] Hood, C.C. (1991). A public management for all seasons. Public Administration. Vol. 69 (Spring). Pp. 3-9.

[12] Greunz, M, J. Haes, B. Schopp, K. Stanoevska (2001). Integrating e-Government Infrastructures through Secure XML Document Containers. Proceedings of the $34^{\text {th }}$ Hawaii International Conference on Information Systems.

[13] Heesen, H.C., V.M.F. Homburg, M. Offereins. (1997). An Agent View on Law. Artificial Intelligence and Law. 5(4). Pp. 323-340.
[14] Van Alstyne, M., E. Brynjolfsson \& S. Madnick. (1995). Why not one big database? Principles for data ownership. Decision Support Systems. 15(4). Pp. 267-284.

[15] Bakos, J.Y., B. Nault (1997). Ownership and Investment in Electronic Networks. Information System Research. 8(4). pp. 321-341.

[16] Pfeffer, J., G.R. Salancik. (1978). The external control of organizations. New York: Harper \& Row.

[17] Allen, D., D. Colligan, A. Finnie, T. Kern (1999). Trust, Power and Inter-Organisational Information Systems: the case of the electronic trading community TransLease. Unpublished Research Report. Rotterdam: Faculty of Business Administration.

[18] Bellamy, C. (1998). ICTs and Governance: Beyond Policy Networks? The Case of the Criminal Justice System. In: Snellen, I.Th.M., W.B.H.J. van de Donk. Public Administration in an Information Age. Amsterdam: IOS Press. Pp. 293 - 306.

[19] Grijpink, J.H.A.M. (1997) Keteninformatisering, met toepassing op de justitiële bedrijfsketen. (Value chain informatization, with application to the juridical supply chain). The Hague: SDU.

[20] Beynon-Davies, P. (1994). Information management in the British National Health Service: The Pragmatics of Strategic Data Planning. International Journal of Information Management, 14(2). pp. 84-94.

[21] Kraemer, K.L., S. Dickhoven, S.F. Tiernet, J.L. King (1987). Datawars: The Politics of Modeling in Federal Policymaking. New York: Columbia University Press. 